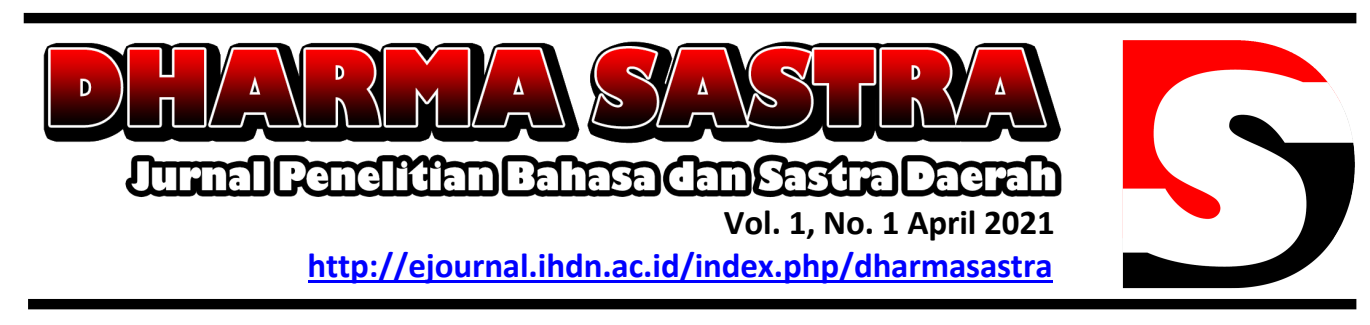

\title{
Kedudukan Perempuan dalam Masyarakat Multikultur, Pada Trilogi Novel Sembalun Rinjani Karya Djelantik Santha
}

\author{
I Gede Gita Purnama A.P
}

Universitas Udayana, Email : penabicara85@gmail.com

\begin{tabular}{l}
\hline \multicolumn{1}{c}{ Info Artikel } \\
\hline Diterima : 27 Maret 2021 \\
Direvisi : 31 Maret 2021 \\
Diterbitkan : 2 April 2021 \\
Keywords: \\
Women Position, \\
Multiculturalism, Literary \\
Criticism of Feminism \\
\end{tabular}

Abstract
Women have been filling the literary space of modern Balinese
literature as an object of storytelling. The role and appearance of
women who have been in the hegemony of patriaki has always been
interesting to talk about from a feminist point of view. The novel
trilogy of Sembalun Rinjani is one of the modern Balinese literary
novels depicting the position of women in a multicultural society.
This novel by Djelantik Santha reflects the duality of the struggle of
female characters in multicultural society to escape from the stigma
of inferior creatures, as well as the image of female characters who
still survive in the hegemony of patriaki.

\section{Pendahuluan}

Perubahan serta kemajuan zaman mengantarkan manusia pada pola kehidupan yang lebih baik dalam segala bidang, maju dalam setiap sektor kehidupan. Perkembangan, kemajuan, serta globalisasi yang menghadirkan multikulturalisme tidak lantas menjadikan urusan gender jadi terlupakan. Sebagaimana yang terjadi pada masyarakat dengan pola pikir yang modern, pergolakan wacana kesetaraan gender tidak pernah sepi. Sejak dulu bahkan hingga kini mungkin juga sampai nanti. Laki-laki selalu berusaha untuk berada di atas perempuan, mengukuhkan dominasi patriaki.

Multikulturalisme yang digiring oleh modernitas membuka peluang besar bagi kaum perempuan untuk belajar banyak dan membuka wawasannya sehingga tidak selalu jadi bulanbulanan kaum laki-laki. Melalui media sastra, kita mampu melihat bagaimana perempuan dilukiskan oleh pengarang. Pengarang sebagai individu sosial membaca dengan cermat setiap fenomena sosial di lingkungannya. Pandangan tentang posisi pengarang pada masyarakat diungkapkan oleh Ratna (2011:60) menyatakan bahwa ada hubungan yang hakiki antara karya sastra dengan masyarakat. Hubungan tersebut disebabkan oleh; a) karya sastra dihasilkan oleh pengarang, b) pengarang itu adalah anggota masyarakat, c) pengarang memanfaatkan kekayaan yang ada dalam masyarakat, dan d) hasilkarya sastra dimanfaatkan kembali oleh masyarakat.

Djelantik Santha merupakan salah satu sastrawan Bali yang tertarik berkarya dalam bidang sastra Bali modern. Salah satu karya Djelantik Santha yang menunjukkan kedudukan 
perempuan dalam masyarakat multikultur adalah Trilogi Novel Sembalun Rinjani. Trilogi ini terdiri atas novel Sembalun Rijani (2000), novel Gita Ning Nusa Alit (2002), dan novel Suryak Suwung Mangmung (2005). Dalam trilogi novel ini, kita bisa melihat bagaimana tokoh-tokoh perempuan dalam lingkungan multikultural memainkan perannya.

Menurut Selden (1986: 130-131), ada lima masalah yang biasa muncul dalam kaitannya dengan teori feminis, yaitu a) masalah biologis, b) pengalaman, c) wacana, d) ketaksadaran, dan e) masalah sosioekonomi. Kritik sastra feminis meliputi penelitian tentang penggunaan teori feminis diharapkan mampu membuka pandangan-pandangan baru terutama berkaitan dengan bagaimana karakter-karakter perempuan diwakili dalam sastra (Ruthven, 1984:30). Selain itu, bagaimana perempuan digambarkan dan bagaimana potensi yang dimiliki perempuan di tengah kekuasaan patriarkhi dalam karya sastra (Ruthven, 1984:40-50).

Berdasarkan pandangan teori feminis di atas, kita akan melihat bagaimana perempuan dalam masyarakat multikultur digambarkan dalam trilogi novel Sembalun Rinjani. Kita juga akan mengetahui kesadaran pengarang laki-laki dalam menyikapi isu kesetaraan gender. Sebab selama ini, stigma perempuan sebagai objek bagi pengarang laki-laki selalu pada posisi yang inferior, tunduk dan lemah.

\section{Metode}

Metode pengumpulan data yang digunakan dalam penelitian ini adalah studi kepustakaan. Pengumpulan data dengan studi kepustakaan menggunakan teknik membaca. Pada saat analisis data, data yang diperoleh diolah dengan menggunakan metode deskriptif analitik. Metode deskriptif merupakan metode yang digunakan untuk mengadakan kajian yang bersifat kualitatif.

\section{Pembahasan}

\section{Perempuan Tangguh: Superioritas Tokoh Perempuan}

Kesetaraan dalam memperoleh kesempatan untuk mengenyam pendidikan formal merupakan salah satu hak yang diperjuangkan perempuan. Melalui pendidikan formal, perempuan mampu meningkatkan status sosialnya, meningkatkan peran sosialnya, baik di keluarga maupun di masyarakat. Tokoh perempuan dalam novel yang menunjukkan konsistensinya dalam mendukung wacana kesetaraan pendidikan antara laki-laki dan perempuan adalah Gusti Biang Ngurah. Gusti Biang Ngurah adalah bibi dari Gusti Ngurah Darsana dan Gusti Ayu Darsini. Namun, karena kedua orang tua Gusti Darsana dan Darsini telah pergi meninggalkan mereka, akhirnya Gusti Biang Ngurah mengasuh mereka layaknya anak sendiri. Gusti Biang Ngurah sangat mendukung kemajuan anak-anaknya khsusnya dalam bidang pendidikan. Bahkan, ia menggadaikan tanah sawahnya untuk mendapatkan biaya pendidikan bagi anak-anaknya.

Gusti Biang Ngurah tidak membedakan tingkat pendidikan anaknya, baik laki-laki maupun perempuan. Baginya, baik anak laki-laki maupun perempuan berhak atas pendidikan yang sama tanpa harus dibatasi oleh dikotomi gender, berikut kutipannya:

"Ibu anak tusing méda-médaang pianak, jawat muani jawat luh. Yén jégeg mabudi masekolah ngalanjutang ka kota, nah lautang. Nyen nawang cening cocok dadi bidan utawi dadi guru ibu tusing kaberatan" (Sembalun Rinjani, hal: 5). ${ }^{1}$

\footnotetext{
1 "Ibu tidak pernah membeda-bedakan anak, baik laki maupun perempuan. Kalau kamu mau melanjutkan sekolah ke kota, ya silah kan. Siapa tahu kamu cocok menjadi bidan atau guru ibu tidak keberatan"
} 
Kutipan di atas menunjukkan betapa terbukanya pemikiran Gusti Biang Ngurah terhadap kesetaraan gender khususnya di bidang pendidikan, meski ia sendiri bukanlah perempuan yang berpendidikan. la bekerja sendiri karena suaminya telah meninggal, kemudian bertindak sebagai orang tua bagi anak-anak yang sejatinya bukan anak kandungnya. Gusti Biang Ngurah mewakili sosok kaum perempuan tangguh yang mampu bertindak tidak hanya sebagai ibu, tetapi juga sebagai ayah bagi anak-anaknya. Peran ayah sebagai kepala keluarga, sebagai pencari nafkah telah dipikul sendiri.

Hak pendidikan yang diberikan oleh Gusti Biang Ngurah pada anak perempuannya menunjukkan pola pikir modern seorang perempuan tradisional, merasa dengan dirinya miskin harta, maka ia berjuang keras bekerja untuk menyekolahkan anak-anaknya. Meskipun tak mampu memberi modal dalam bentuk material, Gusti Biang Ngurah mampu memberikan modal pendidikan (gelar) pada anak perempuannya. Dengan modal pendidikan yang dimiliki perempuan, ia dapat meningkatkan status sosialnnya. Dari modal pendidikan perempuan dapat memperoleh pekerjaan atau menciptakan pekerjaan sehingga memperoleh penghasilan. Hal ini berpengaruh besar ketika kelak ia menjadi istri, perempuan tidak hanya bermodalkan tubuh, tetapi juga berbekalkan modal akademik, modal kultur, dan modal ekonomi sehingga perempuan tidak mutlak bergantung pada suaminya. Akan tetapi justru mampu berkontribusi bagi kehidupan rumah tangga. Kontribusi aktif, baik berupa finansial, material, maupun ideasional, bahkan perempuan mampu menduduki fungsi tulang punggung keluarga mengggantikan laki-laki.

Peran aktif para perempuan yang telah mengenyam pendidikan terlihat jelas dengan terjadinya pergeseran peran gender. Peran gender telah menempatkan suatu polarisasi antara laki-laki dan perempuan sebagai individu yang memiliki fungsinya masing-masing. Para perempuan dikultuskan pada satu peran domestik, bertindak sebagai pengelola rumah tangga, mengurus suami dan anak-anak. Sebaliknya laki-laki berperan pada ranah publik yang menjadikan suami berperan sebagai kepala rumah tangga, pencari nafkah untuk keluarga (Atmadja dan Atmadja, 2005: 122).

Pergeseran peran gender dalam novel terjadi manakala laki-laki tidak mampu berperan aktif sebagai pemain di sektor publik dan fungsinya diambil alih oleh perempuan. Peran perempuan berpendidikan yang menggantikan kedudukan laki-laki sebagai pencari nafkah dilakoni oleh tokoh Marieta Victoria. Ia adalah ibu kandung Meina Victoria, seorang gadis Flores yang menjadi pembantu di keluarga Gusti Ngurah Darsana saat bertugas di Atambua.

Marieta awalnya adalah seorang perawat yang bertugas di Mataram mendampingi Dokter Nurja. Ia memiliki suami bernama Letda Fritse Tondoan yang seorang pensiunan tentara dan kini bekerja sebagai petugas kebun di Mataram. Akibat kerusuhan yang terjadi di Mataram keluarga Marieta terpisah, suaminya meninggal di perkebunan tempatnya bekerja. la pun berpisah dengan anak pertamanya bernama Leonardo yang dibawa Dokter Nurja ke Cakranegara. Sementara itu Marieta yang tengah mengandung pergi ke Atambua bersama Emon Bello sahabat suaminya sewaktu masih menjadi tentara. Setelah menetap di Atambua, Marieta yang tengah mengandung terpaksa harus mengakui Emon Bello sebagai suaminya untuk menghindari gunjingan orang karena mereka hidup serumah. Untuk menghidupi dirinya, Marieta bekerja sebagai pembantu rumah tangga. Setelah anaknya lahir, ia bekerja di panti asuhan sebagai pengurus asrama. Tak hanya untuk menghidupi anaknya, Marieta juga bekerja agar bisa memberi uang pada Emon yang selalu menyiksannya ketika tidak diberi uang. "Emon lakar meres Marieta apang nyak maang pipis yen katuju ia mamotoh, 
mamunyah lan ngalih lonté di pelabuhan" (Gitaning Nusa Alit, hal:215). ${ }^{2}$ Tindakan Emon inilah yang menjadi salah satu simbol intimidasi patriarki terhadap perempuan, intimidasi secara fisik dan batin. Secara fisik Marieta akan disiksa jika tidak memberikan uang pada Emon. Sebaliknya, secara batin Marieta tertekan karena hasil jerih payahnya hanya digunakan untuk bersenang-senang oleh Emon.

Emon ditangkap di pelabuhan karena berjudi dan pengedar cocain. Marieta dan anaknya yang diberi nama Meina akhirnya menetap di panti asuhan. Saat Marieta kehilangan suaminya ia telah memulai hidup baru dengan tinggal bersama laki-laki yang tidak memiliki ikatan apa pun dengannya. la mulai memainkan peranan ganda, sebagai pekerja domestik (mengurus rumah serta anaknya) dan pekerja di ranah publik (sebagai pencari nafkah dan tulang punggung perekonomian). Peranan ganda yang dilakoni Marieta tidak hanya karena ia telah kehilangan suami sebagai pencari nafkah keluarga, tetapi juga karena ia berada dalam intimidasi laki-laki yang kini hidup bersamanya. Memang setelah Emon Bello ditangkap polisi Marieta bisa bebas dari tekanan fisik dan intimidasi patriarki. Namun, peranan gandanya sebagai pekerja rumah tangga dan pencari nafkah tidak bisa dilepaskan begitu saja. Marieta menjadi sosok yang tangguh, mampu bertahan pada peranan gandanya sebagai akibat dari pergeseran peran gender.

Tokoh perempuan lain yang juga menjalankan peranan ganda adalah Diah Rengsi Pitaloka. la adalah seorang gadis Dayak yang menikah dengan Gusti Ngurah Anantha Bhuana, putra pertama Gusti Ngurah Darsana. Menikah dengan laki-laki yang berbeda etnik membuat Diah Rengsi mesti belajar banyak untuk dapat masuk dalam kebudayaan dan lingkungan barunya. Pemberlakuan sistem patriarki menimbulkan implikasi jika laki-laki kawin, maka mereka akan membawa istrinya untuk masuk ke lingkungan keluarganya. Sistem kekeluargaan patrilineal-patrilokal membawa perempuan pada lingkungan baru dengan tidak terlepas pada pembagian kerja di bidang domestik. Kondisi ini menjadikan perempuan harus dapat beradaptasi dengan baik agar mereka dapat diterima di lingkungan baru (Atmadja dan Atmadja, 2005: 111).

Diah Rengsi mampu beradaptasi dengan baik di lingkungan baru keluarga suaminya, belajar banyak tentang adat serta budaya di lingkungan barunya. "Seringan Diah Rengsi sané mamaca lan matakén indik Upakara lan Tattwa agama Hinduné.Utamané indik bebanten nuju Purnama, Tilem." (Suryak Suung Mangmung, hal: 43). ${ }^{3}$ Kemampuan Diah Rengsi beradaptasi dengan lingkungan barunya merupakan salah satu bentuk kemapanannya menjalankan peran domestik sebagai seorang perempuan.

Peranan Diah Rengsi di sektor publik sebagai penopang perekonomian keluarga telah menggeser peranan suaminya. Suami sebagai laki-laki yang seharusnya berperan-biasanya mendominasi- sektor publik kini tergantikan posisinya oleh Diah Rengsi. Diah Rengsi yang telah bekerja di salah satu rumah sakit di Jakarta mampu menjalankan perannya sebagai tulang punggung keluarga memenuhi kebutuhan ekonomi. Hal ini karena suaminya masih kuliah dan tidak bekerja. Akhirnya Diah Rengsilah yang menanggung biaya kehidupan seharihari keluarganya. Meskipun telah menikah, Gusti Ngurah Anantha Bhuana belum mampu menjalankan kewajibannya sebagai kepala keluarga untuk menjadi tulang punggung

\footnotetext{
2 "Emon akan memeras Marieta agar memberinya uang saat ia akan berjudi, mabuk-mabukan dan mencari pelacur di pelabuhan"

3 “Lebih sering Diah Rengsi yang membaca dan bertanya tentang Upakara dan Tattwa agama Hindu. Terutama tentang banten saat Purnama, Tilem"
} 
perekonomian."Raganné durung taler lulus, napi malih makarya mangda nénten setata nglantingin rabi sane ngrereh pangupa jiwa"4 (Suryak Suung Mangmung, hal: 44).

Ketergantungan laki-laki (suami) secara finansial pada perempuan (istri) yang ditunjukkan oleh Gung Anantha membuktikan bahwa perempuan telah mampu menjadi basis ekonomi bagi keluarganya. Kemampuan Diah Rengsi untuk memasuki sektor publik lalu berperan aktif (malah cenderung memegang kendali) dalam mengatasi masalah eekonomi keluarga menunjukkan bahwa ia mampu juga menjalankan peran maskulin sebagai tulang punggung keluarga. Peranan ganda mampu dijalankan dengan baik oleh Diah Rengsi, tidak hanya berkubang pada sektor domestik (mengurus anak, membuat banten, mencuci, dll), tetapi juga mampu berperan aktif di sektor publik (bekerja sebagai perawat dan memenuhi kebutuhan finansial keluarga).

Gusti Biang Ngurah, Marieta Victoria dan Diah Rengsi adalah cermin perempuan yang mampu menunjukkan diri sebagai perempuan yang tangguh dalam masyarakat multikultur. Mereka menunjukkan bahwa perempuan juga mampu memenuhi kebutuhan finansial keluarga meskipun tanpa dukungan laki-laki. Ada peralihan fungsi gender, pergeseran peran ketika laki-laki tidak aktif berperan sebagai tulang punggung keluarga. Perempuan mampu bergerak secara aktif dan dominan dalam memenuhi kebutuhan keluarga, baik secara material maupun moral. Perempuan yang berperan ganda tidak hanya berkutat pada domainnya sebagai individu yang terikat pada urusan domestik. Namun, telah melangkah untuk berperan juga dalam sektor publik yang dulunya didominasi kaum laki-laki. Mereka mampu menunjukkan eksistensinya sebagai perempuan modern yang tidak lagi takluk pada laki-laki. Namun, bangkit dari keterpurukan (Gusti Biang Ngurah dan Marieta Victoria yang ditinggal suaminya) lalu bersaing di ranah publik untuk mendapatkan pengakuan dan pendapatan. Meskipun mereka sendiri tidak sepenuhnya bisa lepas dari keterikatan tugastugas domestik (mencuci, memasak, mengasuh anak, dll). Setidaknya mereka menunjukkan bahwa perempuan tidak selalu berada pada posisi inferior. Perempuan mampu bekerja, mampu mencukupi kebutuhan financial dan moral keluarga tanpa bantuan suami (Diah Rengsi).

Kedudukan perempuan dalam masyarakat Bali yang bernapaskan Hindu sesungguhnya sangat diperhitungkan. Perempuan tidak hanya menjadi pemain tingkat kedua (second player), tetapi duduk bersama dalam kegiatan keseharian yang berkaitan dengan adat dan agama. Hindu memandang perempuan sebagai Shakti (Sanskerta) yang berarti "kekuatan" atau "energi". Perempuan dipandang sebagai sebuah kekuatan atau energi yang menjadikan manusia, bahkan dewa tetap pada posisi mereka, membuat seseorang kuat, atau membuat manusia menjadi orang suci. ${ }^{5}$ Desa-desa Bali Aga ${ }^{6}$ bahkan memiliki larangan untuk berpoligami yang bertujuan untuk melindungi hak-hak perempuan dari dominasi laki-laki.

\footnotetext{
4 "Dia belum juga lulus apalagi bekerja, supaya tidak selalu bergantung pada istri yang mencari nafkah"

${ }^{5}$ Shakti dalam ajaran Hindu adalah pasangan dewa-dewa (istri) yang menjaga kekuatan dewa-dewa tersebut tetap pada tempatnya. Sedikitnya terdapat 40 Shakti dalam kepercayaan Hindu yang termuat di Rig Veda. Frank Morales, 2011, hal. 10-15.

${ }^{6}$ Bali Aga atau disebut juga dengan Bali Mula adalah orang-orang Bali asli yang tidak berasal dari keturunan Jawa (Majapahit). Orang-orang Bali Aga adalah penghuni Bali sebelum akhirnya ditaklukan oleh kerajaan Majapahit melalui ekspansi yang dilakukan Gajah Mada. Bali Aga kini menghuni desa-desa yang kebanyakan berada di pegunungan, di antaranya adalah Tenganan (Karangasem), Bayung Gede (Bangli), Bonyoh (Bangli), dan Umbalan (Bangli).
} 
Larangan-larangan ini tertuang dalam awig-awig $^{7}$ desa yang diatur dengan sangat ketat karena berkaitan langsung dengan hak laki-laki sebagai krama desa ${ }^{8}$ (Sujaya, 2007: vi-vii).

\section{Perempuan Steriotipe: Perempuan yang Tunduk pada Hegemoni}

Modernisasi membawa dampak besar terhadap kedudukan perempuan dalam bentuk gerakan emansipasi yang mencoba menghapus jejak kelam masa silam terhadap marginalisasi fungsi dan peran perempuan. Namun, masih saja menyisakan perempuan-perempuan yang terlelap dalam hegemoni budaya patriakhi. Individu tersebut tidak kuasa (atau enggan) beranjak dari citra feminisme yang menempatkan perempuan pada sisi lemah, pasif, serta tidak mandiri. Konsep ideologi gender rupanya masih membelenggu individu ini dalam ikatan patriarki yang sudah jelas merugikan dirinya. Proses pembentukan citra baku antara feminim dan maskulin menjadi sebuah ideologi gender yang lebih banyak mengakibatkan perempuan secara fisik termarjinalisasi (Mariyah dkk., 2005: 100).

Perempuan seperti ini tidak bergerak aktif dalam merespons arus emansipasi yang turut dibawa oleh multikulturalisme. Mereka tidak turut berkiprah dalam sektor publik dan lebih memilih untuk berkutat pada urusan domestik semata. Tokoh perempuan yang mencerminkan perempuan pasif dalam arti kesetaraan gender dalam trilogi novel Sembalun Rinjani adalah Gusti Biang Suci. Gusti Biang Suci merupakan sosok perempuan yang membiarkan dirinya larut dalam urusan domestik, tidak membuka diri pada pergerakan emansipasi, tidak membuka diri pada pengetahuan lingkungan sehingga akhirnya menyesali diri sebagai akibat perbuatannya.

Gusti Biang Suci adalah perempuan yang bersuamikan seorang pejuang. Namun, ia tidak memahami tugas dan kewajiban seorang pejuang. Saat suaminya berjuang, keluar masuk hutan untuk bergerilya melawan musuh, ia malah menaruh curiga pada suaminya. la menyangka suaminya telah memiliki wanita lain sehingga jarang pulang ke rumah. Pertempuran dengan strategi gerilya memang memaksa suami Gusti Biang Suci untuk tidak menetap pada satu tempat saja. Hal inilah yang tidak dipahami oleh Gusti Biang Suci. Kurang terbukanya wawasan Gusti Biang Suci akan tanggung jawab suaminya menyebabkan rasa curiga yang berlebihan kian tertanam di hatinya. Tanpa dasar bukti yang kuat ia menuduh suaminya berselingkuh lalu pergi meninggalkan suami dan anak pertamanya, padahal saat itu ia sedang mengandung. Gusti Biang Suci memutuskan untuk pergi ke Lombok bersama keluarga besarnya.

Gusti Biang Suci berada pada posisi terhimpit akibat perbuatannya sendiri. la terpaksa menerima ketika dinikahkan dengan sepupunya oleh orang tuanya. Hal ini dilakukan guna menghindari gunjingan orang ketika anak yang dikandungnya lahir tanpa ayah. Terhimpit di antara keterpaksaan menikah dengan orang yang tak dicintai serta mempertahankan nama baik keluarga."Nganti basang ibuné ngenah ngedenang. Ditu lantas anaké lingsir majangkepang ibu ngajak beli Ngurah Gede" (Sembalun Rinjani, hal: 85). ${ }^{9}$ Keputusan pernikahan ini benar ketika alasannya untuk menghindari aib keluarga jika anak yang dikandung Gusti Biang Suci lahir tanpa ayah. Namun, menjadi miris ketika Gusti Biang Suci harus mengorbankan kesempatannya untuk menjadi perempuan bebas dan mandiri. Hal itu terjadi karena dinikahkan dengan laki-laki yang tidak dicintai sehingga kembali termarjinalkan

\footnotetext{
${ }^{7}$ Awig-awig adalah aturan atau tata krama yang dimiliki oleh setiap organisasi sosial tradisional di Bali. Awigawig ada yang bersifat tertulis ada yang tidak tertulis.

${ }^{8}$ Krama desa adalah anggota masyarakat suatu desa adat di Bali. Mereka memiliki hak serta kewajiban yang diatur dalam awig-awig.

9 "Sampai perut ibu terlihat membesar. Di sana lantas orang tua menikahkan ibu dengan Ngurah Gede"
} 
oleh kuasa patriarki. Jalinan rumah tangga ini memang berjalan dengan baik karena cinta akan tumbuh seiring dengan waktu berjalan. Namun, seiring dengan waktu pula, Gusti Biang Suci semakin melemah menghadapi suaminya. la kehilangan bargaining power atas kedudukannya sebagai istri ketika usia senja tiba.

Gusti Ngurah Gede melakukan perselingkuhan dengan pembantu yang bekerja membantu Gusti Biang Suci mengurus peternakannya. Gusti Biang Suci awalnya menentang dan sulit menerima kenyataan pahit ini. Namun, lagi-lagi ia menyerah pasrah pada keadaan. Perselingkuhan Gusti Ngurah Gede terjadi karena Gusti Biang Suci tidak lagi mampu memenuhi hasrat seksual suaminya. Perselingkuhan ini menunjukkan bagaimana Gusti Biang Suci menyerah pada dominasi seksualitas laki-laki. "Pamuputné, miribang saking tan sida nanggehang kayuné, lantas ragané mamitra ngajak Ni Genitri. Sujatiné ibu sedih pesan ngelah madu ulian sesiliban." (Suryak Suung Mangmung, hal: 35$).{ }^{10}$ Sebagai suami, Gusti Ngurah Gede tidak mampu mengendalikan hasrat seksualitasnya hingga akhirnya melakukan perselingkuhan dengan wanita yang lebih muda.

Masa manapouse yang dialami perempuan datang secara alamiah ketika usia perempuan semakin tua dan secara alamiah akan mengurangi hasrat seksualitas perempuan. Hal ini menjadi alasan bagi laki-laki (Gusti Ngurah Gede) untuk menyalurkan hasrat seksualnya pada perempuan lain yang lebih muda. Ironinya adalah seorang perempuan yang menjadi tempat pelampiasan hasrat seksual Gusti Ngurah Gede merelakan tubuhnya tanpa ikatan perkawinan atau transaksi materi. Berdasarkan hal itu, semakin jelas terlihat bahwa Gusti Ngurah Gede hanya memanfaatkan tubuh perempuan sebagai objek seksualitasnya. Sebagai media untuk menyalurkan libido yang tidak lagi mampu ditangani oleh istrinya. Penerimaan Gusti Biang Suci pada keadaan ini semakin menguatkan steriotipe bahwa perempuan merupakan makhluk yang lemah, terjajah oleh lelaki khususnya dalam urusan seks. "Yen ajiné perlu mara ia ngiring ajiné di kubu" (Suryak Suung Mangmung, 35). ${ }^{11}$ Tubuh perempuan dihargai ketika hasrat seksual laki-laki membutuhkan objek, kemudian dilupakan ketika subjek telah menemukan sesuatu yang dicarinya, kenikmatan seksual!

Lemahnya posisi Gusti Biang Suci sebagai seorang perempuan (istri dan ibu) rupanya telah tertanam sebagai sebuah ideologi baginya. Gusti Biang Suci berprinsip bahwa perempuan hanya memiliki hak dan kewajiban atas wilayah domestik, lebih dari itu adalah ranah yang diperuntukkan bagi kaum laki-laki. Keyakinan inilah yang mendorong Gusti Biang Suci untuk melarang anak perempuannya melanjutkan sekolah ke perguruan tinggi. Gusti Ayu Sri Wahyuni adalah putri Gusti Biang Suci yang hendak melanjutkan sekolahnya ke perguruan tinggi. Keinginan ini mendapatkan penolakan dari ibunya. "Yen anak luh sesubané makurenan lakar nutug ané muani, ngurus umahné padidi, patutné ia ngurus kulewargan kurenané"12 (Sembalun Rinjani, 130). Pernyataan yang dilontarkan Gusti Biang Suci menyiratkan bahwa dalam keyakinannya perempuan harus mengurus rumah, suami, dan keluarganya bekerja di sektor publik.

Keinginan Gusti Biang Suci ini mendapat tentangan dari kedua anaknya. Gusti Ayu Sri Wahyuni mendapat dukungan kakaknya, Gusti Ngurah Darsana yang berhasil meyakinkan Gusti Biang Suci bahwa perempuan pun memiliki hak yang sama dengan laki-laki di bidang pendidikan. Meskipun akhirnya mengizinkan anaknya untuk melanjutkan sekolahnya di

\footnotetext{
10 "Akhirnya karena tidak bisa mengendalikan keinginannya, ia berselingkuh dengan Ni Genitri. Sebetulnya ibu sangat sedih dimadu."

11 "Jika ayah menginginkannya, barulah ia menemani ayahmu di rumah".

12 "Kalau anak perempuan setelah bersuami akan ikut suaminya, mengurus rumah, juga mengurus keluarga suaminya."
} 
kedokteran, ia tetap meyakini bahwa tugas perempuan adalah berkutat di ranah domestik semata.

\section{Kesimpulan}

Tokoh perempuan yang hadir dalam trilogi novel Sembalun Rinjani memang tidak selalu hadir sebagai perempuan yang lemah serta turut pada budaya patriarki. Gusti Biang Ngurah, Marieta, serta Diah Rengsi adalah tokoh perempuan yang cukup tangguh untuk lepas dari hegemoni laki-laki. Mereka mampu tampil lebih dominan dari pada laki-laki, tidak hanya bekerja di sektor domestik yang selama ini dikultuskan pada kaum perempuan, tetapi juga di sektor publik. Pada sektor publik, tokoh-tokoh perempuan mampu bekerja lebih baik dari pada laki-laki yang mendampinginya (suami). Mereka mampu mendapatkan materi (uang) yang cukup untuk memenuhi kebutuhan rumah tangga, bahkan mampu menggerakkan ekonomi keluarga.

Tokoh perempuan ini maju dan berjuang mencari tempatnya di sektor publik tanpa dukungan laki-laki. Mereka berusaha sendiri dengan kemampuannya, menjadikan diri mereka tangguh tanpa kehilangan rasa tanggung jawab sebagai seorang perempuan. Mereka mengambil alih tugas laki-laki sebagai kepala keluarga untuk mencari nafkah, mereka mengendalikan perekonomian keluarga karena dari merekalah sumber utama pemasukan ekonomi. Secara sosiologis tokoh-tokoh perempuan ini telah mampu sejajar dengan laki-laki, meskipun secara fisik dan psikologis masih belum mampu menghapuskan hegemoni ideologi patriarki. Tokoh-tokoh perempuan ini menunjukkan jati diri sebagai perempuan modern yang mampu duduk sama rata dengan laki-laki, memiliki kemampuan sama dengan laki-laki, yaitu berkiprah pada ranah publik.

Kedudukan perempuan dalam masyarakat multikutur yang tercermin dalam trilogi novel Sembalun Rinajani telah lebih baik, yaitu hak dan kewajiban kaum perempuan lebih diperhatikan. Perjuangan kaum perempuan yang berpikiran maju melalui gerakan emansipasinya telah mengantarkan harkat serta martabat perempuan ke tempat yang lebih layak, tidak lagi harus berada di bawah laki-laki. Namun, ada juga kaum perempuan yang masih saja enggan beranjak dari bayang-bayang ideologi patriarki. Mereka masih merasa nyaman hanya dengan menjadi objek bagi laki-laki, baik secara fisik, sosiologis, maupun psikologis. Dilema memang ketika di satu sisi kaum perempuan berjuang guna mendobrak batas-batas polarisasi, sedangkan di sisi lain ada juga kaumnya yang masih menerima pengkultusan dirinya sebagai makhluk inferior. Akan tetapi inilah dualitas dalam realitas masyarakat multikultur yang terus akan berkembang ke arah lebih baik seiring dengan membaiknya pola pikir individu-individu di dalamnya.

\section{Daftar Pustaka}

Anwar, Wan. 2007. "Potret Gelap Keluarga Griya dalam Novel Kenanga karya Oka Rusmini." Makalah yang disampaikan pada pelatihan APRESDA Guru Tingkat Nasional.

Atmadja, Nengah Bawa dan Anantawikrama Tungga Atmadja. 2005. "Dekonstruksi Alasan Maknawi Wanita Bali Menjadi Guru dan Implikasinya terhadap Kesetaraan Gender" (dalam Jurnal Kajian Budaya, Vol. 2, No. 3, Januari 2005, hlm. 122). Denpasar: Program S2 dan S3 Kajian Budaya Universitas Udayana.

Atmosuwito, Subijantoro. 1989. Perihal Sastra dan Religiusitas dalam Sastra. Bandung: CV Sinar Baru.

Bandel, Katrin. 2006. Sastra, Perempuan, Seks. Yogyakarta: Jalasutra 
Mariyah, Emiliana dkk. 2005. "Perkawinan Poligini dalam Perspektif Agama dan Gender" (dalam Jurnal Kajian Budaya, Vol. 2, No. 3, Januari 2005, hlm 95 - 107). Denpasar: Program S2 dan S3 Kajian Budaya Universitas Udayana.

Morales, Frank. 2011. "Konsep Shakti: Agama Hindu sebagai Kekuatan Pembebasan bagi Perempuan". Media Hindu. Edisi. 09, Agustus 2011, hlm 10-15). Jakarta: Media Hindu.

Putra, I Nyoman Darma. 2010. Tonggak Baru Sastra Bali Modern. Denpasar: Pustaka Larasan.

Ratna, Nyoman Kutha. 2011. Paradigma Sosiologi Sastra.Yogyakarta: Pustaka Pelajar.

Ruthven, K.K. 1984. Feminist Literary Studies. New York: University of Cambridge.

Santha, Djelantik. 2000. Sembalun Rinjani. Denpasar: Majalah SARAD. . 2003. Gita Ning Nusa Alit. Denpasar: Balai Bahasa. . 2005. Suryak Suwung Mangmung. Denpasar: Balai Bahasa.

Selden, Raman. 1986. A Reader's Guide to Contemporary Literary. Sussex: The Harvester Press.

Semi, Atar. 1988. Anatomi Sastra. Padang: Angkasa Raya.

Sujaya, I Made. 2007. Perkawinan Terlarang, Pantangan Berpoligami di Desa-desa Bali Kuno. Denpasar: Arti Foundation.

Tong, Rosemarie Putnam. 2010. Feminist Tought, Pengantar Paling Komprehensif kepada Arus Utama Pemikiran Feminis. Yohyakarya: Jalasutra. 